\title{
Retrospective and cross-sectional study on the prevalence of malaria in selected areas under elimination program in Dembiya district, North-western Ethiopia
}

Mihretu Tarekegn

Addis Ababa University

Habte Tekie

Addis Ababa University

Sisay Dugassa ( $\sim$ sisaydlw2@gmail.com )

Addis Ababa University https://orcid.org/0000-0002-6951-3299

Yitbarek Wolde-hawariat

Addis Ababa University

\section{Research}

Keywords: Malaria prevalence, malaria control, Anopheles, Plasmodium, malaria risk factors

Posted Date: April 3rd, 2021

DOI: https://doi.org/10.21203/rs.3.rs-376655/v1

License: (c) (i) This work is licensed under a Creative Commons Attribution 4.0 International License. Read Full License 


\section{Abstract}

Background: Ethiopia embarked on combating malaria with an aim to eliminate malaria from low transmission districts by 2030 . This involves malaria vector interventions by implementing mainly indoor residual spraying (IRS) and long-lasting insecticidal nets (LLINs) against endophilic and endophagic female Anopheles mosquitoes. Limited published reports are available about the status of malaria in areas under malaria elimination program in Ethiopia. This study intended to assess the prevalence of malaria in selected areas with a long history of implementing malaria prevention and elimination strategies.

Methods: A cross-sectional parasitological survey was conducted in two selected malaria endemic areas in Dembiya District, Northwest Ethiopia. Thin and thick blood smears collected from 735 randomly selected individuals were microscopically examined for malaria parasites. Six years retrospective malaria data was also collected from the medical records of the health centres. Structured questionnaires were prepared to collect information about the socio-economic data of the population. The data were analysed using SPSS version 20 and $p \leq 0.05$ were considered statistically significant.

Results: The six-year retrospective malaria prevalence trend indicates an overall malaria prevalence of $22.4 \%$, out of which Plasmodium falciparum was the dominant species. From a total of 735 slides examined for the presence of malaria parasites, $3.5 \%(n=26)$ were positive for malaria parasites, in which $P$. falciparum was more prevalent $(n=17 ; 2.3 \%)$, P. vivax $(n=5 ; 0.7 \%)$, and mixed infections $(n=4 ; 0.5 \%)$. Males were 2.6 times more likely to be infected with malaria than females ( $\mathrm{AOR}=2.6 ; 95 \% \mathrm{Cl}: 1.0,6.4)$, and individuals with frequent outdoor activity were 16.4 times more vulnerable than individuals with limited outdoor activities (AOR=16.4, 95\% Cl: 1.8, 147.9). Furthermore, awareness about malaria transmission was significantly associated with the prevalence of malaria.

Conclusions: Malaria is still a public health problem in Dembiya district irrespective of the past and existing vector control interventions. A malaria elimination plan might not be successful unless other alternative intervention tools targeting outdoor malaria transmission are included. For this, continuous monitoring of vectors' susceptibility, density, and behaviour is very important in such areas.

\section{Background}

Malaria is a leading public health problem in Ethiopia, which accounts for $12 \%$ of outpatient consultations and $10 \%$ of health facility admissions [1]. More than half of the population in the country (60\%) lives in malarious areas, and an estimated $68 \%$ of the total population is at risk of malaria infection [2, 3]. The transmission of malaria in Ethiopia is seasonal and unstable, and it varies with altitude and rainfall. In most parts of the country, peak malaria transmission occurs after the main rainy season (July to September). In addition, many areas experience a second minor malaria transmission period following a short rainy season from February to March [1, 2]. Most of the malaria transmissions in Ethiopia occurs in areas below 2000m.a.s.l, but endemic regions greater than $2000 \mathrm{~m}$ are also documented $[4,5]$.

Plasmodium falciparum and $P$. vivax are the dominant malaria parasite species in Ethiopia, which are responsible for $60 \%$ and $40 \%$ of malaria cases, respectively [6-8]. However, $P$. vivax may be more dominant in different localities of the country with cooler climates [9]. In Ethiopia, Anopheles arabiensis is the primary vector of malaria, whereas An. pharoensis, An. funestus and An. nili are secondary vectors in different parts of the country [10].

The government of Ethiopia has made a massive scale-up of malaria control interventions in recent years including diagnostic testing, rapid case treatment using artemisinin-based combination therapy (ACT), prevention and control of malaria among pregnant women using intermittent preventive therapy in pregnancy (IPTp), insecticide-treated bed nets (ITNs), and indoor residual spraying (IRS) [11-14]. This has led to a significant reduction of malaria mortality and morbidity in the country $[12,15]$. However, the progress towards malaria elimination is hampered because of widespread drug resistance by the parasites, and insecticide resistance in the vectors [15]. This calls for repeated malaria prevalence studies in such areas with high vector control interventions, to design additional malaria control and prevention technologies $[6,16]$.

This malaria prevalence study was conducted in two localities in Dembiya district, Northwestern Ethiopia, which are malaria-endemic areas with longstanding vector control interventions [17]. Over the years, malaria treatment and control measures have resulted in a significant reduction of malaria in the district [18]. However, grassroots reports on the prevalence of malaria in such localities with prolonged malaria interventions are scarce. Therefore, this study evaluated the retrospective and present trend of malaria transmission in the selected localities, and identifies socio-economic factors for malaria transmission in the study area.

\section{Methods}

\section{Study area description}


This study was conducted in Dembiya District found in the North Gondar administrative zone of Amhara regional state. The district is located at $12^{\circ} 39^{\prime} \mathrm{N}$ and $37^{\circ} 09^{\prime} \mathrm{E}$. Kola Diba is the capital city of the district, located $750 \mathrm{~km}$ north of Addis Ababa and $35 \mathrm{~km}$ southwest of Gondar city. The southern part of the district is bordered by Lake Tana. The district has 45 localities (the lowest administrative unit in Ethiopia). The population of Dembiya District was estimated to be approximately 271,000 in 2007 , of which $50.9 \%(138,000)$ were male and $49.1 \%(133,000)$ were females. The majority of the population (91\%) lives in rural areas, with most engaging in farming activities; the remaining $9 \%$ live in urban areas. The district has 49,528 rural households with 4.3 mean household sizes [19].

The elevation of Dembiya District is between 1500 to $2600 \mathrm{~m}$ above sea-level. The agro-ecology of the District is midland (woyna-dega) with respective mean annual minimum and maximum temperature of $11^{\circ} \mathrm{C}$ and $32^{\circ} \mathrm{C}$ and the mean annual rainfall ranges from 995 to $1175 \mathrm{~mm}$. Information obtained from the district agricultural bureau indicated that the respective proportion of areas considered as plain, mountainous, valleys, and wetland is $87 \%, 5 \%, 4.8 \%$, and $3.2 \%$. Out of the total area of the District, $31 \%$ is cultivated land, $16 \%$ is none cultivable land, $5.6 \%$ forest and bush, $12.8 \%$ grazing, $8.1 \%$ is covered with water, $20.2 \%$ swamp and $4.3 \%$ is residential areas. The district receives bimodal rainfall, with the short rainy season from March to May and the main rainy season from June to September.

The major crops grown in the District includes teff (Eragrostis teff), maize (Zea mays), barley (Hordeum vulgare), red highland sorghum (Sorghum bicolor), and finger millet (Eleusine Coracana). Besides, legumes and pulses such as chickpeas (Cicer arietinum) and cowpeas (Vigna unguiculata) are also grown in the district. They also grow some cash crops like red paper, niger seed (Guizotia abyssinica), fenugreek

(Trigonella foenum-graecum), black cumin (Nigella sativa), White cumin (Cuminum cyminum), and rice (Oryza sativa) with a limited number of farmlands.

Guramba Bata $\left(12^{0} 21^{\prime} \mathrm{N}\right.$ and $37^{0} 20^{\prime} \mathrm{E}$, altitude < 2000m.a.s.I.) located $7 \mathrm{~km}$ away from Kola Diba town. A seasonal river persisted until the end of December serving as one of tributaries to Lake Tana. Guramba Bata has one health post and one health centre, 1113 households with 6008 inhabitants (2974 are male and 3034 are females) in 2017/18 G.C (unpublished health office report) (Figure 1).

Arebiya $\left(12^{0} 20^{\prime} \mathrm{N}\right.$ and $37^{0} 22^{\prime} \mathrm{E}$, altitude < 2000m.a.s.I.) is located $17 \mathrm{~km}$ away from Kola Diba town. The Megech River is one of the most important rivers serving as a water source during a dry season and drains into Lake Tana. Within 1976 households, the locality has a total of 8632 inhabitants (4298 are male and 4384 are females) in 2018/19G.C. There is one health post in the locality (unpublished health office report) (Figure 1).

Study Design. A retrospective study was conducted to determine the six-year (2012 to 2017) of malaria prevalence by reviewing reports at Guramba Bata health centre and Arebiya health post. A cross-sectional parasitological survey was conducted in the two study localities of Dembiya district (Guramba Bata and Arebiya) following the end of the long rainy season (September to October, 2018). The two study sites were selected based on their long history of implementing vector control strategies such as IRS and LLINs.

\section{Retrospective malaria data collection}

To assess the retrospective trend of malaria prevalence in the study areas implementing IRS and LLINs vector intervention measures, a sixyear malaria retrospective data (2012-2017) was obtained from Guramba Bata health centre and Arebiya health post. The retrospective malaria prevalence data in the two localities were recorded from microscopic and RDT techniques which were implemented in the health facilities to confirm the presence of Plasmodium parasite in the blood samples.

\section{Sample size determination for active case detection}

The sample size (n) for estimating a population proportion of a small finite population was used to determine the sample size [20].

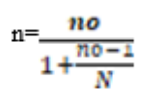

Where $\mathrm{n}$ is the minimum sample size for a small population and $\mathrm{n}_{\mathrm{o}}$ is the sample size for a larger population, $\mathrm{N}$ is the population size ( $\mathrm{N}$ for Guramba Bata $=6008$ and $\mathrm{N}$ for Arebiya $=8632$ ) and $n_{0}$ is calculated using a single point proportion formula. i.e.

$$
n o=\frac{z^{2} * p(1-p)}{d^{2}}
$$

Where, $p=$ prevalence of malaria (50\%), $d=$ margin of error (0.05); Z= standard score corresponds to 1.96 


$$
\begin{gathered}
n o=\frac{1.96^{2} 0.5(1-0.5)}{0.05^{2}}=385 \\
\mathrm{n}_{2}=\frac{385}{1+\frac{385-1}{6008}}=365
\end{gathered}
$$

and

$$
\mathrm{n}_{2}=\frac{385}{1+\frac{385-1}{8632}}=370
$$

Where $n_{1}$ is the sample size for Guramba Bata study site and $n_{2}$ is the sample size for Arebiya study site.

\section{Blood sample collection and prevalence study}

Blood samples were taken from 365 individuals from Guramba Bata and 370 individuals from Arebiya study sites. These individuals were randomly selected from 160 households, considering 4.3 average persons to household of the Amhara region [19].

Thick and thin smears from finger-prick blood samples were prepared from a total of 735 individuals by well-trained laboratory technicians, from randomly selected households at the end of the rainy season (October - December, 2018). All thin smears were air dried and fixed with methanol in the field. Both thick and thin blood smears were stained with $3 \%$ Giemsa solution for 30 minutes in staining jars in the laboratory. The stained slides were rinsed with tap water and placed in an upright position to dry. The stained thick and thin films were examined with 100x oil immersion objective under a light microscope. The thick blood smear samples were first examined for the presence of Plasmodium parasites to determine whether the sample is positive or negative. When samples were positive, thin blood smears were examined for species identification [21].

\section{Socio-economic survey}

A structured questionnaire was prepared to collect information about socio-economic data of the study participants while taking blood samples. Questionnaires were filled by field assistants in consultation with the head of a household during blood sample collection.

\section{Statistical analysis}

The data on retrospective and prospective prevalence of malaria parasites in the two study sites, different age groups, sexes, years and species type were entered using Microsoft excel data sheet and were analysed using SPSS version 20 (Armonk, NY: IBM Corp). Chi squire test was used to compare the difference in frequency of malaria prevalence between independent variables (sex, localities, and age). Association between independent variables with dependent variables was analysed using bivariate logistic regression analysis. Multivariate logistic regression was used to analyse the relative contribution of each independent variable to the dependent variable at $p \leq 0.05$.

\section{Results}

\section{Retrospective trends of malaria prevalence}

Out of 2,157 individuals who visited the two health facilities seeking treatment and suspected to have malaria, $22.4 \%(n=484)$ were positive for malaria parasites (Table 1). Microscopic and RDT results indicated that $19.4 \%(n=281)$ individuals in Arebiya and $28.7 \%(n=203)$ individuals in Guramba Bata were infected with malaria parasites during the six-year period (2012-2017).

There were significant differences in malaria cases among the age groups in both health facilities $\left(\chi^{2}=111.8, d f=3, p=0.000 ; \chi^{2}=231.7, d f=3\right.$, $\mathrm{p}=0.000$ ). Malaria was more prevalent in individuals between the 18-64 age groups in both health facilities. Malaria parasites were detected in 28.5\% ( $n=226)$ individuals in Arebiya health post, and 67.1\% ( $n=143)$ individuals in Guramba Bata health centre in the 18-64 age group (Table 1). On the other hand, relatively low number of malaria cases was recorded in the 6-17 years age groups ( $7.2 \%$ in Arebiya health post and $9.3 \%$ in Guramba Bata health centre) (Table 1). The difference in malaria cases between sexes were statistically significant in both Arebiya health post $\left(\chi^{2}=102.3, d f=1, p=0.000\right)$ and Guramba Bata study sites health centre $\left(\chi^{2}=21.7, d f=1, p=0.000\right)$. Higher malaria cases were recorded in males (27.3\% and $35.9 \%$, respectively) than in females during the six-year period in both health facilities (Table 1$)$. Furthermore, $P$. falciparum was detected in individuals of all age groups, but it was predominant in individuals between the 18-64 years age group (23.3\% and 
53.3\% in Arebiya and Guramba Bata respectively). P.vivax was frequently recorded in children less than 5 years of age group in both study localities (Table 1).

The lowest malaria cases in Arebiya health post $(10.9 \%$; $=31)$ were recorded in 2016 , while the highest malaria cases $(41.9 \%$; $n=72)$ were encountered in 2017. Similarly, lower malaria cases $(11.6 \% ; n=11)$ were detected in 2016 with highest $(47.4 \%$; $n=72)$ malaria cases were recorded in 2017 in Guramba Bata health centre (Figure 2).

Plasmodium falciparum was the predominant species in the study sites during the six year period (2012-2017) (Figure 3) with the highest $P$. falciparum malaria cases $(35.8 \% ; n=116)$ recorded in 2017. $P$. vivax and mixed infections were recorded in relatively lower magnitude in both sites during the six-year period (Figure 3).

\section{Prevalence of malaria parasites from blood sample examination}

Out of the total 735 thick and thin blood smears taken from individuals who participated in the study, 3.5\% $(n=26)$ were positive for malaria parasites. The results from the cross sectional survey indicate that there were no statistically significant difference in percent malaria prevalence between the two localities $\left(\chi^{2}=0.06, d f=1, p=0.814\right)$. The prevalence of malaria infection in Guramba Bata and Arebiya study areas were $3.8 \%(n=14)$ and $3.2 \%(n=12)$ respectively (Table 2$)$. Plasmodium falciparum was the predominant malaria parasite $(2.3 \%, n=17)$ in the study area, followed by $P$. vivax $(0.7 \%, n=5)$, and mixed infections $(0.5 \%, n=4)$.

The frequency of malaria infection among the age groups was statistically significant in Arebiya study site $\left(\chi^{2}=8.3, \mathrm{df}=3, \mathrm{p}=0.040\right)(\mathrm{Table} 2)$. Malaria was more prevalent in the age group $>15$ years old at this study site (5.8\%). Whereas, in Guramba Bata study site the age groups $>15$ were more infected with malaria $(5 \%)$ than the other, but it was not statistically significant $\left(\chi^{2}=2.32, d f=3, p=0.509\right)(T a b l e ~ 2)$. Males were more infected with malaria in Arebiya $(5 \%)$ and the difference in malaria case between sexes were statistically significant $\left(\chi^{2}=4.3, d f=1, p=\right.$ 0.039) (Table 2). Similarly, in Guramba Bata study sites males were more infected with malaria (4.4\%) than females, though the difference was not statistically significant $\left(\chi^{2}=0.31, \mathrm{df}=1, \mathrm{p}=0.579\right)$ (Table 2)

\section{Socio-demographic data and Malaria risk factor analysis}

Blood samples for microscopic examination were collected from 735 randomly selected individuals from the two study localities of which $50.3 \%(n=370)$ were from Arebiya and $49.7 \%(n=365)$ were from Guramba Bata. Males comprised $52 \%(n=382)$ while females were $48 \%(n=$ 353 ) of individuals in the sample (Table 3). The age groups, below 15, 5-9, 10-14, and above 15 accounted for $7.3 \%(n=54), 18.9 \%(n=139)$, $17.8 \%(n=131)$, and $55.9 \%(n=411)$ of the study participants respectively. The majority of the study participants were farmers $(86.7 \%$; $n=637)$ and the rest $(13.3 \% ; n=98)$ were merchants. Most of the study participants $(45.9 \% ; n=341)$ were not educated. All study participants were from rural areas (Table 3$)$.

Bivariate and multivariate analysis indicated that risk factors such as sex, age, outdoor activity in the evening, awareness about malaria transmission, the frequency of LLIN distribution, and application of IRS were significantly associated with malaria prevalence $(P<0.05)$. However, respondent's occupation, educational level, the last time respondents received IRS were not significantly associated with malaria transmission ( $P>0.05$; Table 4).

Males were 2.6 times more likely to be infected with malaria than females (AOR $=2.6,95 \%$ Cl: $1.04,6.41)$ and individuals with high outdoor activity were 16.4 times more vulnerable than individuals with limited outdoor activities (AOR=16.4, 95\% Cl: 1.82, 147.85). Respondents who are not aware of malaria transmission and control were highly infected with malaria than those who were aware of it (AOR=0.3, $95 \% \mathrm{Cl}$ : $0.12-$ 0.82). The last time respondents received LLINs (before a year) was associated with a low level of malaria prevalence in the study area (Table 4).

\section{Discussion}

This study evaluated the six-year retrospective data of malaria prevalence from health facility records in Guramba Bata and Arebiya localities, where vector control strategies such as IRS and ITN have been implemented for more than a decade. A snapshot cross-sectional malaria survey was also conducted to determine the level of malaria transmission and the malaria parasites that prevail in the study area. Results from both retrospective and cross-sectional studies indicate that malaria is a public health problem in the area. The overall percent malaria cases detected in the retrospective malaria study were $22.4 \%(n=484)$ with percent malaria cases peaking towards $2017(44.4 \%)$ despite of the ongoing IRS and LLINs malaria vector control strategies implemented in the study area. A relatively higher percent of malaria cases were reported from a similar retrospective study in the nearby Kola Diba health centre (39.6\%) [22], and Serbo health centre (43.8\%) [23]. However, this result is higher than a retrospective study conducted in Metema hospital [24] and Kombolcha [25], where the prevalence was 17\%, and $7.5 \%$ respectively. 
The overall prevalence of malaria from this cross-sectional study was $3.5 \%(26 / 735)$ and $P$. falciparum was the predominant malaria parasite, this is comparable with the3.9\% prevalence reported from a cross-sectional study conducted in Awassa Town [26]. The result of the crosssectional study was lower than the 5.3\% prevalence of malaria reported in Gondar Town [27], and the 5.2\% malaria prevalence from Jimma Town [28].

The six-year retrospective data indicated that malaria prevalence varied from year to year, with relatively lower malaria cases recorded in 2013, 2015 and 2016. The reduced number of malaria cases during these years could be associated with the accumulated effect of scaled-up malaria control interventions and improved community awareness in the study area. The relatively higher number of malaria cases reported in 2017 indicated an increase in malaria prevalence in the study area, irrespective of continued malaria vector control interventions. This is in agreement with the existing scenarios advocating that malaria remains a public health problem in Ethiopia even though intensive vector intervention strategies were implemented [29]. This could possibly be because of inappropriate utilization of vector intervention strategies, the development of insecticide resistant malaria vector and development of resistance in Plasmodium parasites to the existing drugs.

The species specific prevalence in this study showed that $P$. falciparum was the dominant, whereas $P$. vivax and mixed prevalence holds the second and third position respectively. This is in line with the fact that $P$. falciparum is the dominant parasite in many parts of Ethiopia with altitude below $2000 \mathrm{~m}$ a.s.I [30]. Similar trend of Plasmodium parasite distributions were reported from Gilgel-Gibe [31] and children from Northern Ethiopia [32] and migrant laborers from North-western Ethiopia [33]. Retrospective studies from Kola Diba health centre [22], Serbo health centre [23], Metema hospital [24], Kombolcha [25], and Tselemti Woreda [34] and a survey from different part of Ethiopia [35] also support this study finding. However, reports showed that $P$. vivax was the dominant species in some part of Ethiopia [28, 36, \& 37].

The retrospective and prospective studies indicated that malaria infections were more prevalent in males than in females. Similar studies indicated that males were more infected with malaria than females in different part of Ethiopia [38-41] and in Kenya [42]. It was presumed that individual behaviour s, environmental and socio-economic factors contribute to transmission of malaria in Ethiopia [43, 44]. Likewise, malaria was more prevalent in individuals above the age group of $\geq 15$. This is in agreement with a retrospective study conducted in Kombolcha [25] and Kola Diba health centres [22]. Male individuals at these productive ages are actively involved in outdoor activities such as agriculture and cattle herding, in the evening which makes them vulnerable to outdoor Anopheles mosquito biting. Male individuals usually spend the night outside the house tending cattle in the study sites. These outdoor activities at night were predictors associated with malaria transmission in the study areas. Similarly, different reports indicated that outdoor activities in the evening contributed to high malaria transmission [41, 43] mainly due to the fact that individuals with outdoor activities are exposed to outdoor biting by Anopheles mosquitoes [45]. During this study, a substantial number of children were also infected with Plasmodium parasites during this study, which indicates the endemicity of malaria in the study area.

The current study showed that poor awareness and knowledge about malaria prevention and control contributed to the prevailing malaria transmission in the study area. Similar reports indicated that awareness about malaria was associated with malaria transmission in Ethiopia [41] and Kenya [42]. This urges for a continuous need to educate and increase awareness of the local communities about malaria transmission towards improved malaria prevention and control strategies.

\section{Conclusions}

The prevalence of malaria in Dembiya District, where vector control strategies such as long-lasting insecticide treated bed nets and indoor residual sprays have been implemented for over three decades, was determined using prospective and retrospective data. The respective overall prevalence of Plasmodium infection from a retrospective and prospective study was $22.4 \%$ and $3.5 \%$, indicating malaria remains a public health problem in the district. Factors such as outdoor activity and poor knowledge about malaria transmission contributed to malaria infection in the district. Therefore, the national malaria elimination program would not be possible unless other additional alternative of malaria prevention and control methods targeting outdoor vector control and awareness creation are designed. In addition, a continuous monitoring of vector ecology and behaviour is important to design a holistic approach to malaria control strategies.

\section{Abbreviations}

LLINs: Long lasting insecticide treated bed nets

IRS: Indoor residual spray

Cl: Confidence interval

$\chi 2$ : chi squire 
df: Degree of freedom

RDT: Rapid diagnosis test

IPTp: intermittent preventive therapy in pregnancy

\section{Declarations}

\section{Ethics approval and consent to participate}

Ethical clearance was obtained from Addis Ababa University, institutional ethical review board of the College of Natural and Computational Sciences (Ref No CNSDO/692/10/2018). Written consent was obtained from the head of the house hold and other study participants before sampling. Individuals proved to be positive for malaria during blood film examination were treated with antimalarial drug prescribed by physicians.

\section{Consent for publication}

Not applicable

\section{Availability of data and materials}

The data sets supporting the conclusions of this article are available at Addis Ababa University College of Natural and Computational Sciences.

\section{Competing Interest}

The authors declare that there is no conflict of interest.

\section{Funding}

This study was financed by Addis Ababa University.

\section{Authors' contributions}

MT, HT, YW and SD designed the study. HT, YW and SD supervised and MT conducted the experiments. MT conducted the statistical analyses. MT developed first draft, HT, YW and SD revised the manuscript. All authors read and approved the final manuscript.

\section{Acknowledgements}

The authors want to acknowledge Addis Ababa University for providing a financial support for this research and Woldia University for providing a study leave. We also express our appreciation for Kola Diba city health centre staff members for their technical assistance.

\section{References}

1. Federal Ministry of Health (FMoH): Health and health-related indicators,2009/2010 Addis Ababa, Ethiopia: Ministry of Health of Ethiopia. 2011. https://www.dktethiopia.org/sites/default/files/PublicationFiles/Health\%20and\%20Health\%20Related\%20Indicators\%202005\%20E.C.pdf. Accessed 24 February 2019.

2. Initiative PM. President's malaria initiative Ethiopia: Malaria operational plan FY 2019 USAID.https://reliefweb.int/report/ethiopia/president-s-malaria-initiative-ethiopia-malaria-operational-plan-fy-2019. Accessed 10 April 2019.

3. World health organization. Malaria (WHO). https://www.who.int/countries/eth/areas/cds/malaria/en/. Accessed 10 April 2019.

4. Ghebreyesus TA, Haile M, Witten KH, Getachew A, Yohannes M, Lindsay SW, Byass P. Household risk factors for malaria among children in the Ethiopian highlands. Trans R Soc Trop Med Hyg. 2000;1(1):17-21. https://doi.org/10.1016/S0035-9203(00)90424-3. 94(.

5. Woyessa A, Teshome GM, Ali A. An indigenous malaria transmission in the outskirts of Addis Ababa, Akaki Town and its environs. EJHD. 2004;18(1).

6. Federal Ministry of Health (FMoH). National malaria elimination Roadmap. 2017. Addis Ababa,Ethiopia.Downloads\Documents\MalariaEliminationRoadmapEthiopiafinalH_3. pdf. Accessed 10 April 2019. 
7. Yalew WG, Pal S, Bansil P, Dabbs R, Tetteh K, Guinovart C, Kalnoky M, Serda BA, Tesfay BH, Beyene BB, Seneviratne C. Current and cumulative malaria infections in a setting embarking on elimination: Amhara, Ethiopia. Malar J. 2017;16(1):242. DOI 10.1186/s12936017-1884-y.

8. Federal Ministry of Health (FMoH). National Five Year Strategic Plan for Malaria Prevention and Control in Ethiopia, 2006-2010, Ministry of Health, Addis Ababa,

Ethiopia,2006.http://www.cdbph.org/documents/who_evipnet_documents_guideline_Ethiopia\%20National_Five_Year_Strategic_Plan.pdf. Accessed 25 April 2019.

9. Deress T, Girma M. Plasmodium falciparum and Plasmodium vivax Prevalence in Ethiopia: A systematic review and meta-analysis. Malar Res Treat. 2019; 7065064. doi: 10.1155/2019/7065064.

10. Gillies MT, Coetzee M. A Supplement to the Anophelinae of Africa South of the Sahara. Publ S Afr Inst Med Res. 1987;55:1-43.

11. Abeku TA, Helinski ME, Kirby MJ, Kefyalew T, Awano T, Batisso E, Tesfaye G, Ssekitooleko J, Nicholas S, Erdmanis L, Nalwoga A. Monitoring changes in malaria epidemiology and effectiveness of interventions in Ethiopia and Uganda: Beyond Garki Project baseline survey. Malar J. 2015;14(1):337. https://doi.org/10.1186/s12936-015-0852-7.

12. Aregawi M, Lynch M, Bekele W, Kebede H, Jima D, Taffese HS, Yenehun MA, Lilay A, Williams R, Thomson M, Nafo-Traore F. Time series analysis of trends in malaria cases and deaths at hospitals and the effect of antimalarial interventions, 2001-2011, Ethiopia. PLoS One. 2014; 9 (11).

13. Yimer F, Animut A, Erko B, Mamo H. Past five-year trend, current prevalence and household knowledge, attitude and practice of malaria in Abeshge, south-central Ethiopia. Malar J. 2015;14(1):230.

14. Federal Ministry of Health (FMoH). The 2011 National Malaria Indicator Survey. Addis Ababa: Federal Democratic Republic of Ethiopia Ministry of Health; 2011. https://www.ephi.gov.et/images/downloads/2011ethiopiamistechsummary.pdf. Accessed 5 May.

15. Taffese HS, Hemming-Schroeder E, Koepfli C, Tesfaye G, Lee MC, Kazura J, Yan GY, Zhou GF. Malaria epidemiology and interventions in Ethiopia from 2001 to 2016. Infect Dis Poverty. 2018;7(1):1-9. https://doi.org/10.1186/s40249-018-0487-3.

16. Gosling R, Chimumbwa J, Uusiku P, Rossi S, Ntuku H, Harvard K, White C, Tatarsky A, Chandramohan D, Chen I. District-level approach for tailoring and targeting interventions: a new path for malaria control and elimination. Malar J. 2020;19:1-7. https://doi.org/10.1186/s12936-020-03185-w.

17. Tulu AssefaNega. Determinants of malaria transmission in the highlands of Ethiopia: the impact of global warming on morbidity and mortality ascribed to malaria. PhD thesis. J Trop Med Hyg. 1996. DOI: https://doi.org/10.17037/PUBS.00682286.

18. Toyama Y, Ota M, Molla G, Beyene BB. Sharp decline of malaria cases in the BurieZuria, Dembia, and Mecha districts, Amhara Region, Ethiopia, 2012-2014: descriptive analysis of surveillance data. Malar J. 2016;15(1):104. DOI 10.1186/s12936-016-1133-9.

19. Central statistical agency. 2007. http://www.csa.gov.et/census-report/complete-report/census-2007.

20. Israel GD. Determining sample size. 1992. Fact Sheet PEOD. 2014;6.

21. Warrell DA, Gilles HM. Essential malariology. CRC Press; 2017 Dec 14.

22. Alemu A, Muluye D, Mihret M, Adugna M, Gebeyaw M. Ten year trend analysis of malaria prevalence in Kola Diba, North Gondar, Northwest Ethiopia. Parasit Vectors. 2012;5(1):173. https://doi.org/10.1186/1756-3305-5-173.

23. Karunamoorthi K, Bekele M. Prevalence of malaria from peripheral blood smears examination: a 1-year retrospective study from the Serbo Health Centre, KersaWoreda. Ethiopia J Infect Public Health. 2009;2(4):171-6. https://doi.org/10.1016/j.jiph.2009.08.005.

24. Ferede G, Worku A, Getaneh A, Ahmed A, Haile T, Abdu Y, Tessema B, Wondimeneh Y, Alemu A. Prevalence of malaria from blood smears examination: a seven-year retrospective study from Metema Hospital, Northwest Ethiopia. Malar Res Treat. 2013. https://doi.org/10.1155/2013/704730.

25. Gebretsadik D, Feleke DG, Fiseha M. Eight-year trend analysis of malaria prevalence in Kombolcha, South Wollo, north-central Ethiopia: a retrospective study. Parasit Vectors. 2018;11(1):55. https://doi.org/10.1186/s13071-018-2654-6.

26. Alemu G. "Prevalence of Malaria and its influencing factors in Awassa District, Southern Ethiopia." PhD diss., Addis Ababa University, 2006.http://etd.aau.edu.et/handle/123456789/11783.

27. Tilaye T, Deressa W. Prevalence of urban malaria and associated factors in Gondar Town, Northwest Ethiopia. EMJ. 2007;45(2):151-8.

28. Alemu A, Abebe G, Tsegaye W, Golassa L. Climatic variables and malaria transmission dynamics in Jimma town, South West Ethiopia. Parasit Vectors. 2011;4(1):30. https://doi.org/10.1186/1756-3305-4-30.

29. Benelli G, Beier JC. Current vector control challenges in the fight against malaria. Acta Tropica. 2017;174:91 - 6. https://doi.org/10.1016/j.actatropica.2017.06.028.

30. President's Malaria Initiative. Ethiopia, malaria operational plan FY 2015.https://www.pmi.gov/docs/default-source/default-documentlibrary/malaria operational-plans/fy-15/fy-2015-ethiopia-malaria-operational-plan.pdf?sfvrsn = 3. Accessed 22 April 2020. 
31. Yewhalaw D, Legesse W, Van Bortel W, Gebre-Selassie S, Kloos H, Duchateau L, Speybroeck N. Malaria and water resource development: the case of Gilgel-Gibe hydroelectric dam in Ethiopia. Malar J. 2009;8(1):21. https://doi.org/10.1186/1475-2875-8-21.

32. Ghebreyesus TA, Haile M, Witten KH, Getachew A, Yohannes AM, Yohannes M, Teklehaimanot HD, Lindsay SW, Byass P. Incidence of malaria among children living near dams in northern Ethiopia: community based incidence survey. Bmj. 1999;11(7211):663-6. https://doi.org/10.1136/bmj.319.7211.663. 319 ).

33. Aschale Y, Mengist A, Bitew A, Kassie B, Talie A. Prevalence of malaria and associated risk factors among asymptomatic migrant laborers in West Armachiho District, Northwest Ethiopia. Research reports in tropical medicine. 2018;9:95. http://dx.doi.org/10.2147/RRTM.S165260.

34. Shiferaw M, Alemu M, Tedla K, Tadesse D, Bayissa S, Bugssa G. The Prevalence of Malaria in Tselemti Wereda, North Ethiopia: A Retrospective Study. Ethiop. 2018; 28(5). http://dx.doi.org/10.4314/ejhs.v28i5.4.

35. Abeku TA, Van Oortmarssen GJ, Borsboom G, de Vlas SJ, Habbema JD. Spatial and temporal variations of malaria epidemic risk in Ethiopia: factors involved and implications. Acta Tropica. 2003;87(3):331-40. https://doi.org/10.1016/s0001-706x(03)00123-2.

36. Woyessa A, Deressa W, Ali A, Lindtjørn B. Prevalence of malaria infection in Butajira area, south-central Ethiopia. Malar J. $2012 ; 11(1)$ :84. https://doi.org/10.1186/1475-2875-11-84.

37. Tadesse F, Fogarty AW, Deressa W. Prevalence and associated risk factors of malaria among adults in East Shewa Zone of Oromia Regional State, Ethiopia: a cross-sectional study. BMC Public Health. 2018;18(1):25. https://doi.org/10.1186/s12889-017-4577-0.

38. Dufera M, Dabsu R, Tiruneh G. Assessment of malaria as a public health problem in and around ArjoDidhessa Sugar Cane Plantation area, Western Ethiopia. BMC Public Health. 2020;20(1):1-0. https://doi.org/10.1186/s12889-020-08784-5.

39. Tesfahunegn A, Berhe G, Gebregziabher E. Risk factors associated with malaria outbreak in LaelayAdyabo district northern Ethiopia, 2017: case-control study design. BMC Public Health. 2019;19(1):484. https://doi.org/10.1186/s12889-019-6798-x.

40. Alemu K, Worku A, Berhane Y, Kumie A. Men traveling away from home is more likely to bring malaria into high altitude villages, northwest Ethiopia. PLoS One 2014; 9(4). https://doi.org/10.1371/journal.pone.0095341.

41. Agegnehu F, Shimeka A, Berihun F, Tamir M. Determinants of malaria infection in Dembia district, Northwest Ethiopia: a case-control study. BMC Public Health. 2018;18(1):480. https://doi.org/10.1186/s12889-018-5370-4.

42. Sultana M, Sheikh N, Mahumud RA, Jahir T, Islam Z, Sarker AR. Prevalence and associated determinants of malaria parasites among Kenyan children. Trop Med Health. 2017;45(1):25. https://doi.org/10.1186/s41182-017-0066-5.

43. Graves PM, Richards FO, Ngondi J, Emerson PM, Shargie EB, Endeshaw T, Ceccato P, Ejigsemahu Y, Mosher AW, Hailemariam A, Zerihun M. Individual, household and environmental risk factors for malaria infection in Amhara, Oromia and SNNP regions of Ethiopia. R Soc Trop Med Hyg. 2009;103(12):1211-20. https://doi.org/10.1016/j.trstmh.2008.11.016.

44. Deressa W, Ali A, Berhane Y. Household and Socio-economic factors associated with childhood febrile illnesses and treatment seeking behaviour in an area of epidemic malaria in rural Ethiopia. R Soc Trop Med Hyg. 2007;101(9):939-47.

https://doi.org/10.1016/j.trstmh.2007.04.018.

45. Kibret S, Alemu Y, Boelee E, Tekie H, Alemu D, Petros B. The impact of a small-scale irrigation scheme on malaria transmission in Ziway area, Central Ethiopia. Trop Med Int Health. 2010;15(1):41-50. https://doi.org/10.1111/j.1365-3156.2009.02423.x.

\section{Tables}

Table 1. A six years retrospective trend of malaria cases in the two localities of Dembiya District (2012- 2017). 


\begin{tabular}{|c|c|c|c|c|c|c|c|c|c|c|}
\hline \multicolumn{11}{|c|}{ No. of malaria parasite positive cases (values in parenthesis are \%malaria cases) } \\
\hline $\begin{array}{l}\text { Study } \\
\text { sites }\end{array}$ & \multicolumn{5}{|c|}{ Arebiya } & \multicolumn{5}{|c|}{ Guramba Bata } \\
\hline \multirow[t]{2}{*}{ Age } & No. & P.f (\%) & P.v(\%) & Mixed & Total & No. & P.f (\%) & P.v(\%) & Mixed & Total \\
\hline & Examined & & & (\%) & $+\operatorname{ve}(\%) *$ & Examined & & & (\%) & $+\operatorname{ve}(\%){ }^{* *}$ \\
\hline$<5$ & 63 & $2(3.2)$ & $4(6.3)$ & 0 & $6(9.5)$ & 66 & $9(13.6)$ & $8(12.1)$ & 0 & $17(25.8)$ \\
\hline $6-17$ & 553 & $23(4.2)$ & $17(3.1)$ & 0 & $40(7.2)$ & 418 & $23(5.5)$ & $8(1.9)$ & $8(1.9)$ & $39(9.3)$ \\
\hline $18-64$ & 792 & 187(23.6) & $27(3.4)$ & $12(1.5)$ & $226(28.5)$ & 213 & $114(53.5)$ & $20(9.4)$ & $9(4.2)$ & $143(67.1)$ \\
\hline$>65$ & 41 & $9(21.9)$ & 0 & 0 & $9(21.9)$ & 11 & 0 & $4(36.2)$ & 0 & $4(36.4)$ \\
\hline \multirow[t]{2}{*}{ Total } & 1449 & $221(15.3)$ & 48(3.3) & $12(0.8)$ & $281(19.4)$ & 708 & 146 & 40 & $17(2.5)$ & $203(28.7)$ \\
\hline & & & & & & & $(20.6)$ & $(5.6)$ & & \\
\hline \multirow[t]{2}{*}{ Sex } & No. & P.f (\%) & P.v (\%) & Mixed & Total +ve & No. & P.f (\%) & P.v(\%) & Mixed & Total +ve \\
\hline & Examined & & & (\%) & $(\%)^{\square}$ & Examined & & & $(\%)$ & $(\%)^{\text {पा }}$ \\
\hline \multirow[t]{2}{*}{ Male } & 931 & 207 & 36 & $11(1.2)$ & $254(27.3)$ & 398 & 110 & 23 & $10(2.5)$ & 143 (35.9) \\
\hline & & $(22.2)$ & (3.9) & & & & $(27.6)$ & $(5.8)$ & & \\
\hline \multirow[t]{2}{*}{ Female } & 518 & $14(2.7)$ & 12 & $1(0.2)$ & $27(5.2)$ & 310 & 36 (11.6) & 17 & $7(2.3)$ & $60(19.4)$ \\
\hline & & & $(2.3)$ & & & & & $(5.5)$ & & \\
\hline \multirow[t]{2}{*}{ Total } & 1,449 & 221 & 48 & $12(0.8)$ & $281(19.4)$ & 708 & 146 & 40 & $17(2.4)$ & 203 (28.7) \\
\hline & & (15.3) & (3.3) & & & & $(20.6)$ & $(5.6)$ & & \\
\hline
\end{tabular}

$*=\chi^{2}=111.8, \mathrm{df}=3, \mathrm{p}=0.000 ; * *=\chi^{2}=231.7, \mathrm{df}=3, \mathrm{p}=0.000 ; \square=\chi^{2}=102.3, \mathrm{df}=1, \mathrm{p}=0.000 ; \mathrm{a}=\chi^{2}=21.7, \mathrm{df}=1, \mathrm{p}=$ 0.000

Table 2. Prevalence of malaria from the cross-sectional study in the two localities of Dembiya District (October-November, 2018). 


\begin{tabular}{|c|c|c|c|c|c|c|c|c|c|c|c|}
\hline \multicolumn{12}{|c|}{ Number and proportions of microscopic malaria parasite positive blood samples } \\
\hline \multicolumn{3}{|c|}{ Study sites } & \multicolumn{3}{|c|}{ Arebiya } & \multicolumn{6}{|c|}{ Guramba Bata } \\
\hline Age & No. & P.f(\%) & P.v(\%) & Mix & Total +ve & Age & No. & P.f (\%) & P.v(\%) & $\operatorname{Mix}(\%)$ & Total \\
\hline & Examined & & & (\%) & $(\%)^{*}$ & & Examined & & & & +ve(\%)** \\
\hline$<5$ & 30 & 0 & 0 & 0 & 0 & $<5$ & 24 & $1(4.2)$ & 0 & 0 & $1(4.2)$ \\
\hline $5-9$ & 76 & 0 & 0 & 0 & 0 & $5-9$ & 63 & $1(1.6)$ & 0 & 0 & $1(1.6)$ \\
\hline $10-14$ & 74 & $1(1.4)$ & 0 & 0 & $1(1.4)$ & $10-14$ & 57 & 0 & $1(1.8)$ & 0 & $1(1.8)$ \\
\hline$\geq 15$ & 190 & $6(3.2)$ & $2(1.1)$ & $3(1.6)$ & $11(5.8)$ & $\geq 15$ & 220 & $8(3.6)$ & $2(0.9)$ & $1(0.5)$ & $11(5)$ \\
\hline Total & 370 & $7(1.9)$ & $2(0.5)$ & $3(0.8)$ & $12(3.2)$ & Total & 365 & $10(2.7)$ & $3(0.8)$ & $1(0.3)$ & $14(3.8)$ \\
\hline \multirow[t]{2}{*}{ Sex } & No. & P.f & P.v & Mix & Total +ve & Age & No. & P.f (\%) & P.v & Mix & Total +ve \\
\hline & Examined & $(\%)$ & $(\%)$ & $(\%)$ & $(\%)^{\square}$ & & Examined & & $(\%)$ & $(\%)$ & $(\%)^{\square \square}$ \\
\hline \multirow[t]{2}{*}{ Male } & 200 & $6(3)$ & 1 & $3(1.5)$ & $10(5)$ & Male & 182 & $4(2.2)$ & 3 & $1(0.5)$ & $8(4.4)$ \\
\hline & & & $(0.5)$ & & & & & & $(1.6)$ & & \\
\hline \multirow[t]{2}{*}{ Female } & 170 & 1 & 1 & 0 & $2(1.2)$ & Female & 183 & $6(3.3)$ & 0 & 0 & $6(3.3)$ \\
\hline & & $(0.6)$ & $(0.6)$ & & & & & & & & \\
\hline \multirow[t]{2}{*}{ Total } & 370 & 7 & 2 & $3(0.8)$ & $12(3.2)$ & Total & 365 & 10 & 3 & $1(0.3)$ & $14(3.8)$ \\
\hline & & $(1.9)$ & $(0.5)$ & & & & & $(2.7)$ & $(0.8)$ & & \\
\hline
\end{tabular}

$*=\chi^{2}=8.3, \mathrm{df}=3, \mathrm{p}=0.040 ; * *=\chi^{2}=2.32, \mathrm{df}=3, \mathrm{p}=0.509 ; \square=\chi^{2}=4.3, \mathrm{df}=1, \mathrm{p}=0.039 ; \mathrm{a}=\chi^{2}=0.31, \mathrm{df}=1, \mathrm{p}=0.579$

Table 3. Socio-demographic data of the study participants in the two localities of Dembiya District. 


\begin{tabular}{|c|c|c|c|}
\hline \multirow{2}{*}{$\begin{array}{l}\text { Variables } \\
\text { Sex }\end{array}$} & \multicolumn{2}{|c|}{ Study sites } & \multirow[t]{2}{*}{ Total (\%) } \\
\hline & Arebiya & Guramba Bata & \\
\hline Male & 200 & 182 & $382(52)$ \\
\hline Female & 170 & 183 & $353(48)$ \\
\hline Total & $370(50.3 \%)$ & 365 (49.7\%) & 735 \\
\hline \multicolumn{4}{|l|}{ Age } \\
\hline$<5$ & 30 & 24 & $54(7.3)$ \\
\hline $5-9$ & 76 & 63 & 139 (18.9) \\
\hline $10-14$ & 74 & 57 & $131(17.8)$ \\
\hline$\geq 15$ & 190 & 221 & $411(55.9)$ \\
\hline Total & 370 & 365 & 735 \\
\hline \multicolumn{4}{|l|}{ Occupation } \\
\hline Farmer & 332 & 305 & $637(86.7)$ \\
\hline Merchant & 38 & 60 & $98(13.3)$ \\
\hline Total & 370 & 365 & 735 \\
\hline \multicolumn{4}{|l|}{ Educational status } \\
\hline No formal education & 146 & 195 & $341(46.4)$ \\
\hline Primary school attendees & 119 & 104 & $223(30.3)$ \\
\hline Secondary school attendees & 71 & 48 & $119(16.2)$ \\
\hline More than secondary & 34 & 18 & $52(7.1)$ \\
\hline Total & 370 & 365 & 735 (100) \\
\hline
\end{tabular}

Table 4. Bivariate and multivariate analysis of factors associated with malaria infection in selected localities of Dembiya District. 


\begin{tabular}{|c|c|c|c|c|c|c|}
\hline \multirow[t]{2}{*}{ Variables } & \multirow[t]{2}{*}{ Category } & \multirow{2}{*}{$\begin{array}{l}\text { Total } \\
\text { Examined }\end{array}$} & \multirow{2}{*}{$\begin{array}{l}\text { Positive } \\
\text { (\%) }\end{array}$} & \multicolumn{2}{|l|}{ OR $(95 \% \mathrm{CI})$} & \multirow[b]{2}{*}{$\begin{array}{l}\mathrm{p}- \\
\text { value }\end{array}$} \\
\hline & & & & COR & AOR & \\
\hline \multirow[t]{2}{*}{ Sex } & Female & 353 & $8(2.3)$ & 1 & 1 & \\
\hline & Male & 382 & $18(4.7)$ & $2.13(0.92-4.97)^{*}$ & $2.58(1.04-6.41)$ & 0.041 \\
\hline \multirow[t]{6}{*}{ Age } & $<5$ & 54 & 0 & 1 & 1 & \\
\hline & $5-9$ & 139 & $1(0.7)$ & $0.38(0.02-$ & $0.31(0.02-5.27)$ & 0.417 \\
\hline & & & & $6.252)^{*}$ & & \\
\hline & $10-14$ & 131 & $3(2.3)$ & $0.82(0.07-9.26)$ & $0.53(0.04-6.48)$ & 0.617 \\
\hline & $\geq 15$ & 413 & $22(5.3)$ & $2.99(0.39-$ & $2.15(0.27-16.92)$ & 0.466 \\
\hline & & & & 22.69) & & \\
\hline \multirow[t]{3}{*}{ Occupation } & Farmer & 637 & $25(3.9)$ & $3.96(0.53-$ & $4.16(0.49-35.22)$ & 0.191 \\
\hline & & & & 29.58) & & \\
\hline & Merchant & 98 & $1(1)$ & 1 & 1 & \\
\hline \multirow[t]{4}{*}{ Educational status } & No education & 341 & $14(4.1)$ & $1.07(0.24-4.85)$ & $1.19(0.24-5.93)$ & 0.837 \\
\hline & Primary & 223 & $6(2.7)$ & $0.69(0.14-3.53)$ & $0.87(0.16-4.74)$ & 0.873 \\
\hline & Secondary & 119 & $4(3.4)$ & $0.87(0.15-4.90)$ & $1.58(0.25-10.02)$ & 0.629 \\
\hline & $>$ Secondary & 52 & $2(3.8)$ & 1 & 1 & \\
\hline \multirow[t]{3}{*}{ Outdoor activity } & Yes & 571 & $25(4.4)$ & $7.46(1.00-$ & 16.42(1.82- & 0.013 \\
\hline & & & & $55.50)^{*}$ & 147.85) & \\
\hline & No & 164 & $1(0.6)$ & 1 & 1 & \\
\hline Awareness & Yes & 441 & $12(2.7)$ & 1 & 1 & \\
\hline transmission & No & 286 & $14(4.9)$ & $1.87(0.85-4.11)^{*}$ & $3.17(1.22-8.24)$ & 0.018 \\
\hline \multirow[t]{2}{*}{ Period of receiving last IRS } & $<6$ month & 541 & $20(3.7)$ & 1 & 1 & \\
\hline & 6-12 month & 194 & $6(3.1)$ & $0.83(0.33-2.10)$ & $1.98(0.66-5.91)$ & 0.221 \\
\hline Period of receiving last & $<6$ month & 16 & $3(18.8)$ & 1 & 1 & \\
\hline \multirow[t]{4}{*}{ LLIN } & 6-12 month & 15 & $4(26.7)$ & $1.58(0.288-$ & $3.32(0.47-23.74)$ & 0.231 \\
\hline & & & & $8.61)$ & & \\
\hline & More & 704 & $19(2.7)$ & $0.12(0.032-$ & $0.12(0.02-0.57)$ & 0.008 \\
\hline & year & & & $0.46)^{*}$ & & \\
\hline
\end{tabular}

*: Indicates significant values at $\mathrm{p} \leq 0.05$

Figures 


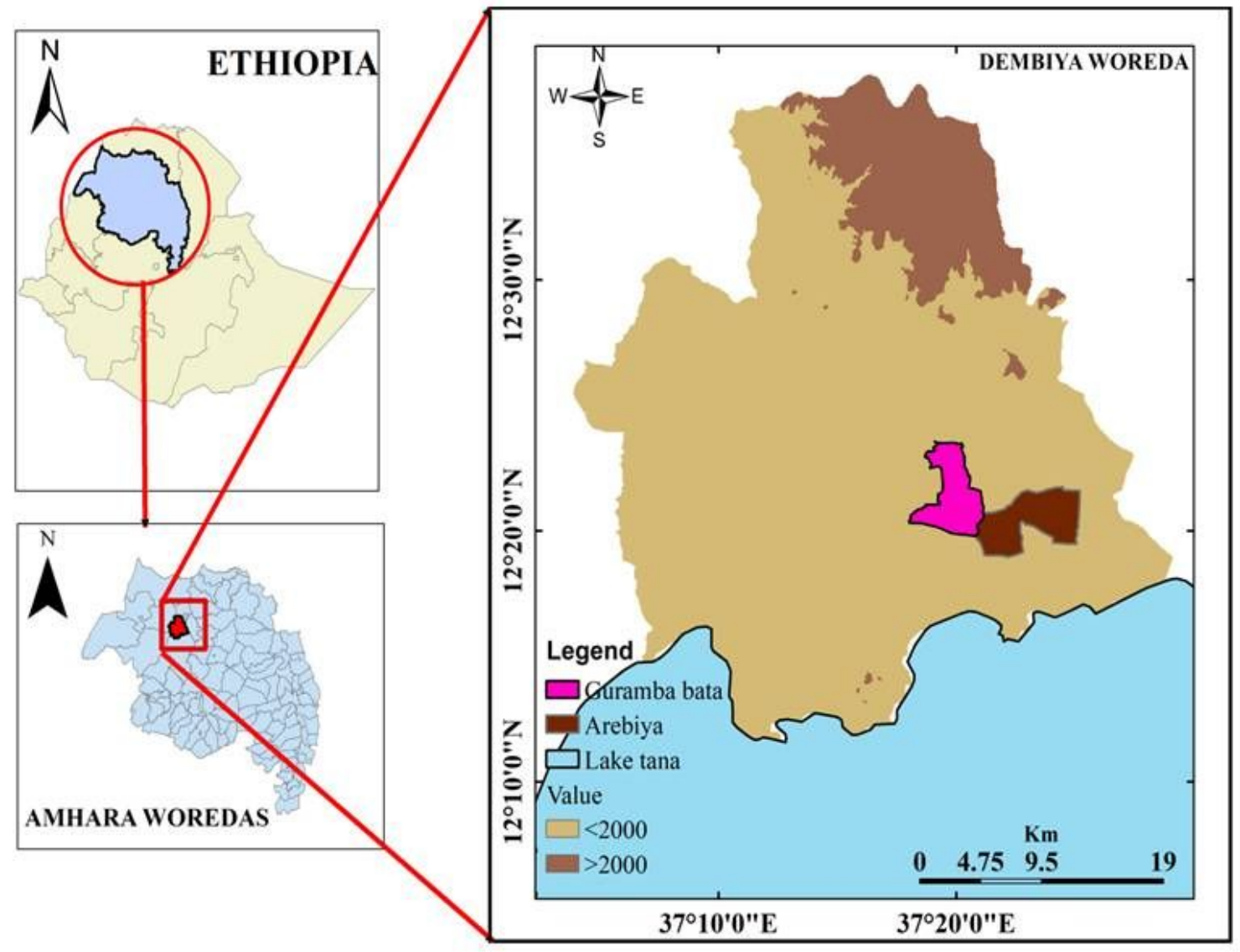

Figure 1

Study area map. Note: The designations employed and the presentation of the material on this map do not imply the expression of any opinion whatsoever on the part of Research Square concerning the legal status of any country, territory, city or area or of its authorities, or concerning the delimitation of its frontiers or boundaries. This map has been provided by the authors. 


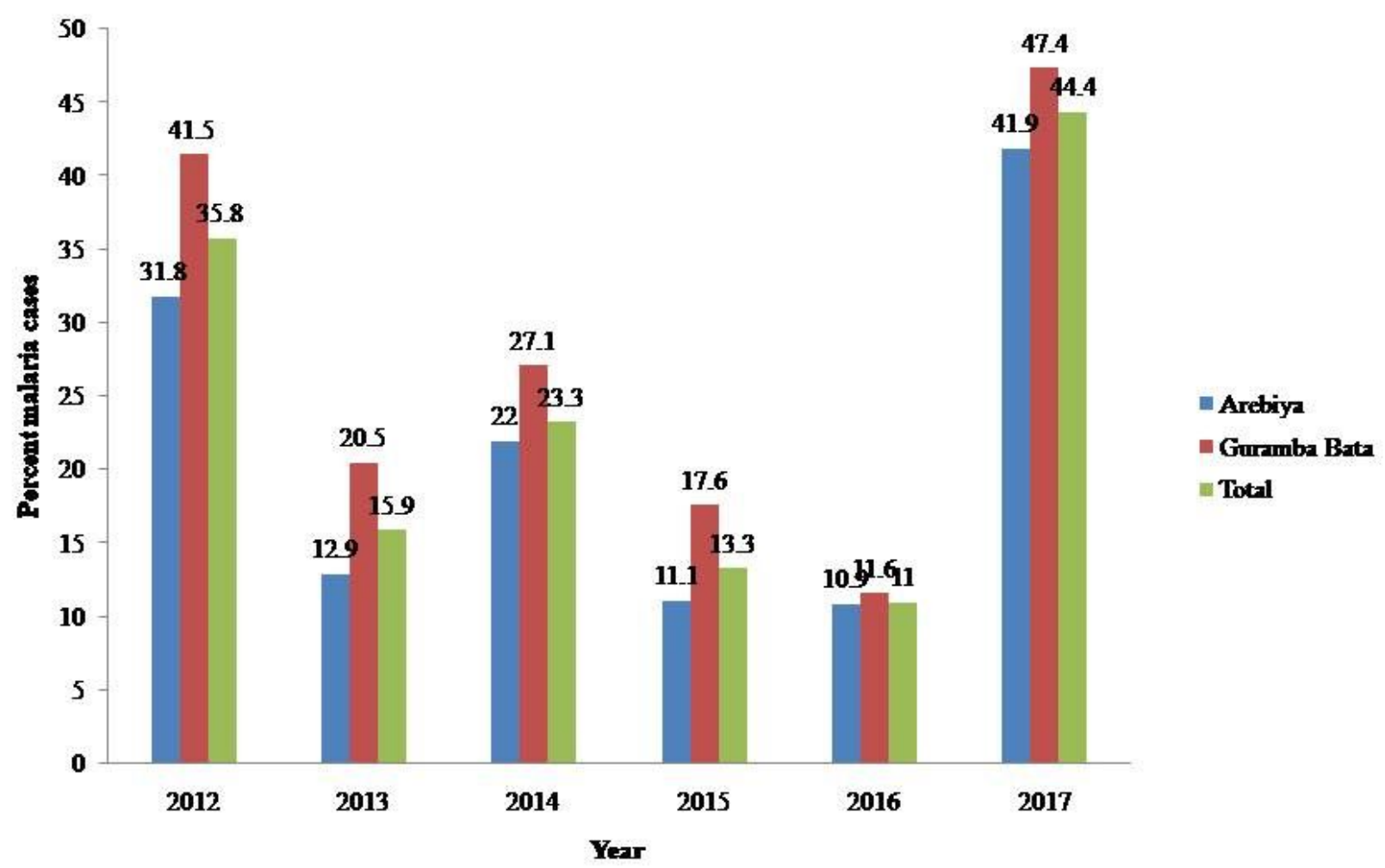

Figure 2

Six-year annual percent malaria cases reported in Arebiya and Guramba Bata (2012 - 2017). 


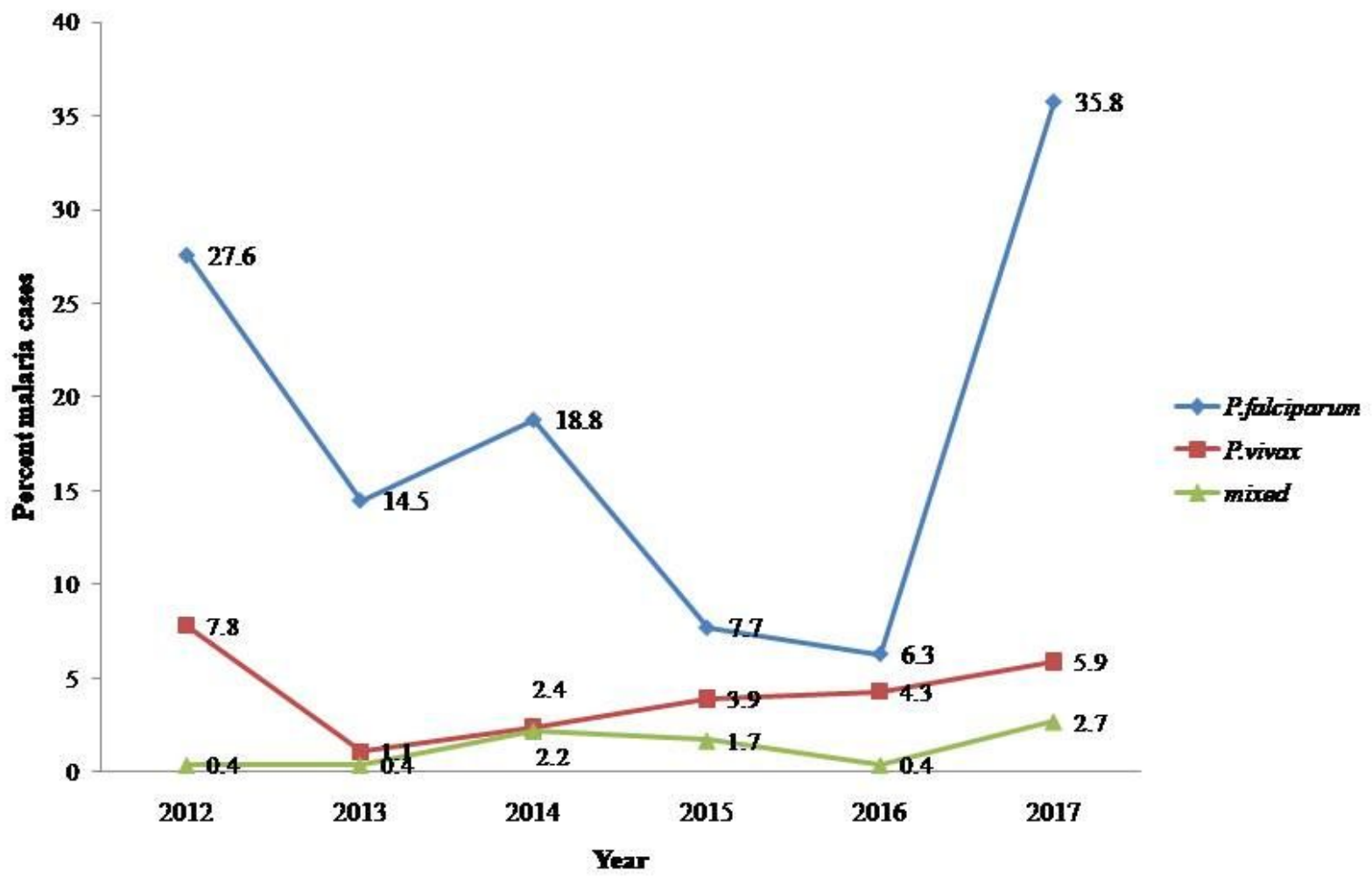

Figure 3

Six-year annual species specific prevalence of malaria parasites reported in Arebiya and Guramba Bata (2012 - 2017). 